\title{
Risk factors for un-investigated dyspepsia among primary care patients in northern Nigeria
}

\author{
*Solomon $\mathrm{OA}^{1}$, Ajayi $\mathrm{AO}^{2}$
}

1. Department of Family Medicine, University Teaching Hospital, Ado Ekiti, Nigeria

2. Department of Medicine, University Teaching Hospital, Ado Ekiti, Nigeria

\begin{abstract}
Background: Many risk factors have been speculated to be associated with uninvestigated dyspepsia amongst different population groups. Some of which have been subjected to epidemiological survey while others remain unevaluated.

Objective: We evaluated some of the documented risk factors amongst patient presenting with uninvestigated dyspepsia and compared with a matched group without dyspepsia in a primary care setting.

Methods: The study was a matched case controlled study. 103 consecutive patient aged between 18 and 50 years that presented with dyspepsia (cases) were enrolled. These were matched by age and sex with the same number of subjects without dyspepsia (controls). Data were collated using a structured questionnaire

Odds ratios and p-values were used to determine the significance of documented categorical risk factors associated with dyspepsia using two by two tables. For risk factors that were continuous variables the means, standard deviations and pvalues were used. Risk factors with their p-values $<0.2$ were entered into logistic regression to identify those independently associated with dyspepsia.

Result: H.pylori seropositivity was $22.3 \%$ and $13.6 \%$ among cases and controls respectively $(\mathrm{p}=0.10)$. Pepper intake $(\mathrm{p}$ $<0.0001)$ and tea intake $(\mathrm{p}=0.0002)$ and greater years of education $(\mathrm{p}=0.0065)$ were significantly associated with dyspepsia. H. pylori seropositivity was not related to the risk of developing dyspepsia.

Conclusion: Helicobacter pylori seropositivity was not found to be a significant contributor to risk of developing dyspepsia among the studied population contrary to general belief. Pepper intake, tea intake and greater years of education were found to significant contributors to dyspepsia.
\end{abstract}

Key words: Risk factors, Helicobacter pylori, Dyspepsia, Nigeria

African Health Sciences 2013; 13(4): 1007 - 1011 http://dx.doi.org/10.4314/ahs.v13i4.21

\section{Introduction}

Dyspepsia is an important, common and demanding clinical problem. ${ }^{1,2}$ According to an international consensus meeting, dyspepsia is defined as pain or discomfort centred in the upper abdomen, that is, in or around the midline. Pain in the right or left hypochondrium is not considered dyspepsia. ${ }^{3}$

Different population based studies on the prevalence of dyspepsia have attempted to identify common symptoms and epidemiological risk factors for uninvestigated dyspepsia. Among various parameters that have been studied in association with prevalence of dyspepsia, age has not been identified as a predictor of dyspepsia (UD or FD). ${ }^{4}$ Most population studies have found an equal ratio between males and females, especially where UD is concerned. Several studies, in different populations, however

\section{*Corresponding author:}

Solomon Olusoji Abidemi

Department of Family Medicine

University Teaching Hospital, Ado Ekiti

Nigeria.

E-mail: abide7000@yahoo.co.uk have noted a consistent female preponderance with dyspepsia ${ }^{5,6,7,8,9}$.

Though a common practice worldwide, regular smoking has not been consistent in its association with dyspepsia. ${ }^{10}$ However, in surveys of patients with UD regular smoking has been identified as a risk factor in populations in U.S, Canada, U.K and India. ${ }^{4,6,11,12}$ Smoking has also been identified as clear risk factor for peptic ulcer disease. ${ }^{13}$ Regular alcohol intake has been shown to be associated with dyspepsia in vast majority of surveys. However in the Asia-Pacific region, only population studies in India and New Zealand showed definite association between alcohol and uninvestigated dyspepsia. ${ }^{4,14}$

Non steroidal anti-inflammatory drugs (NSAID) have been identified as an independent risk factor for UD and thought to be responsible solely for about $4 \%$ of dyspepsia in a British population study ${ }^{12}$ similar association was observed in a study in the US between uninvestigated dyspepsia and use of NSAIDs and aspirin. ${ }^{6}$ The effect of caffeine intake 
on dyspepsia has also been considered, with surveys from US and Europe, reporting that excessive coffee or tea intake has not been shown to be related to the presence of dyspepsia or UD. ${ }^{5,6,11,12,15}$ A Canadian study showed that heavy intake of cola was associated with markedly increased prevalence of dyspepsia. ${ }^{11}$ An explanation for this observation may be that the greater quantities of caffeine in cola can be consumed more readily, or it may be a non-caffeine related compound which is responsible for the dyspeptic symptoms. ${ }^{16}$

The benefit of eradicating Helicobacter pylori infection in peptic ulcer disease has been established convincingly ${ }^{17}$ whereas its potential influence in uninvestigated dyspepsia in the general population has been dealt with only in a limited number of studies yielding conflicting results ${ }^{18-23}$

\section{Methods}

One hundred and three patients aged between 18 and 50 years, presenting newly at a General outpatient clinic with uninvestigated dyspepsia according to ROME II which define dyspepsia as pain or discomfort centred in the upper abdomen, that is, in or around the midline. Pain in the right or left hypochondrium is not considered dyspepsia ${ }^{24}$ and without any other gastrointestinal symptoms (cases), matched by age and sex with same number without dyspepsia (controls) were enrolled for the study. Patients with either heartburn or regurgitation were considered to have gastro-oesophageal reflux disease and were excluded. Both cases and controls were screened for $\mathrm{H}$. pylori using ELISA kit.

Ethical approval was obtained from Ethical committee of Aminu Kano Teaching Hospital.
Voluntary written informed consent was obtained from each participant

A pretested structured questionnaire that contain participants biodata, symptoms of dyspepsia and risk factors was administered to those enrolled with dyspepsia and those without dyspeptic symptoms. Data were entered, checked and analyzed in Epi Info 3.3.2 software (CDC, Atlanta, GA, USA). Odds ratios and $\mathrm{p}$-values were used to determine the significance of documented categorical risk factors associated with dyspepsia using two by two tables. For risk factors that were continuous variables the means, standard deviations and $\mathrm{p}$ - values were used. Risk factors with their $\mathrm{p}$-values $<0.2$ were entered into logistic regression to identify the risk factors independently associated with dyspepsia.

\section{Results}

Twenty three $(22.3 \%)$ of the 103 cases were seropositive to H.pylori infection compared to14 $(13.6 \%)$ out of 103 controls. This was not statistically significant, $\mathrm{p}=0.10$ (table 1$)$. Three $(2.9 \%)$ of the 103 cases were smokers compared with $8(7.8 \%)$ out of 103 controls. This was not statistically significant, $\mathrm{p}$ $=0.12$ (table 1$)$.

Two $(1.9 \%)$ of the cases drank alcohol compared with $4(3.9 \%)$ control, $\mathrm{p}=0.34$ (table 1$)$.

Eight among cases $(7.8 \%)$ had used non steroidal antiinflammatory drugs (NSAID) for a minimum of one week prior to 30 days before enrolment compared with $7(6.8 \%)$ controls, $\mathrm{p}=0.79$ (table 1$)$

Number of meal per day ranged among cases between one and six with means $( \pm \mathrm{SD})$ of $3.04 \pm 0.71$ meals while among controls it ranged between two and four with means $( \pm \mathrm{SD})$ of $2.94 \pm 0.50, \mathrm{p}=0.32$ (table 1$)$.

Table 1: Risk factors for Uninvestigated dyspepsia

\begin{tabular}{|c|c|c|}
\hline Risk factors & OR $(95 \%$ CI $)$ & Pvalue \\
\hline H.pylori & $1.83(0.88-3.79)$ & 0.10 \\
\hline Smoking & $0.36(0.09-1.40)$ & 0.12 \\
\hline Drinking & $0.49(0.09-2.74)$ & 0.34 \\
\hline NSAID usage & $1.16(0.40-3.31)$ & 0.79 \\
\hline Eat much pepper & $3.78(2.12-6.74)$ & $<0.0001 *$ \\
\hline No. of meal per day & Means ( \pm ) & \\
\hline Case & $3.04 \pm 0.71$ & \\
\hline Control & $2.94 \pm 0.50$ & 0.32 \\
\hline \multicolumn{3}{|c|}{ No. of Kolanut per week } \\
\hline Case & $1.33 \pm 5.21$ & 0.71 \\
\hline Control & $0.89 \pm 3.50$ & \\
\hline \multicolumn{3}{|c|}{ No. of Coffee drinks per week } \\
\hline Case & $1.36 \pm 3.57$ & 0.45 \\
\hline Control & $0.75 \pm 2.03$ & \\
\hline \multicolumn{3}{|c|}{ No. of Tea drinks per week } \\
\hline Case & $7.82 \pm 6.83$ & $0.0002 *$ \\
\hline Control & $4.55 \pm 3.60$ & \\
\hline
\end{tabular}


Kolanut eaten per week among cases ranged from none to thirty five nuts per week with means $( \pm \mathrm{SD})$ of $1.38 \pm 5.21$ while it ranged from none to twenty five with means $( \pm S D)$ of $0.89 \pm 3.50, \mathrm{p}=0.71$ (table 1)

Number of coffee drinks taken per week by cases was between none and twenty one, with means $( \pm \mathrm{SD})$ of $1.36 \pm 3.57$ compared to that drank by controls which was between none and fourteen drinks with means $( \pm \mathrm{SD})$ of $0.75 \pm 2.03, \mathrm{p}=0.45$. (table 1)

Number tea drinks drank per week by cases ranged from none to forty two drinks per week with means $( \pm \mathrm{SD})$ of $7.82 \pm 6.83$, while it ranged from none to fourteen drinks per week among controls with means $( \pm \mathrm{SD})$ of $4.55 \pm 3.60, \mathrm{p}=$ 0.0002. (table 1) Sixty six (64.1\%) out of 103 cases claimed they or people close to them believed they eat much pepper compared to $33(32.0 \%)$ out of 103 controls, $\mathrm{p}<0.0001$ (table 1 )

When logistic regression was used to determine the degree of significance of years of education, $H$. pylori seropositivity, eating of much pepper and tea drinking as independent risk factor for having uninvestigated dyspepsia; years of education, eating of much pepper and tea drinking remained significantly associated with uninvestigated dyspepsia(table 2).

Table 2: Logistics regression of factors associated with uninvestigated dyspepsia

\begin{tabular}{lllll}
\hline Risk factors & OR (95\% CI) & Coefficient & Std. Error & P- value \\
\hline H.pylori seropositivity & $1.61(0.71-3.62)$ & 0.4730 & 0.4149 & 0.2543 \\
Education (yrs) & $1.09(1.02-1.16)$ & 0.0815 & 0.0330 & $0.0136^{*}$ \\
Tea drinking (week) & $1.17(1.08-1.26)$ & 0.1530 & 0.0392 & $0.0001^{*}$ \\
Eat much Pepper & $4.31(2.29-8.10)$ & 1.4605 & 0.3219 & $<0.0001^{*}$ \\
\hline
\end{tabular}

* Significant $\mathrm{P}$ value

\section{Discussion}

Among possible risk factors for uninvestigated dyspepsia examined in this study, years of education high pepper intake and high tea intake were found to be independently significant risk factors for dyspepsia. No significant association was found between $H$. pylori infection, smoking, drinking of alcohol, use of NSAID, number of meals eaten per day, number of kolanut eaten per week and number of coffee drinks per week, and uninvestigated dyspepsia in this study.

The significance of high number of years spent to acquire whether Western or Arabic education was among those who had dyspepsia compared to their counterparts without is contrary to findings in Britain where lower education level was associated with uninvestigated dyspepsia. This could possibly be due to increase affluence and openness to embrace other dietary practices like eating of much pepper ${ }^{25}$ that might predispose to uninvestigated dyspepsia therefore further studies into the role of education as a risk factor in dyspepsia in this environment will be of benefit.

The effect of high pepper intake on development of uninvestigated dyspepsia agreed with available evidence that spices, in particular black pepper, red pepper, and chilli powder may produce dyspepsia. ${ }^{26}$
This effect of pepper is similar to that observed in a study by Solanke in 1973 where it was observed that 'ulcer are less prevalent in Northern Nigerians than in Southern regions because of greater use of red pepper in the diet of the latter'. ${ }^{26}$ The reversal in this observation might possibly be due to change in dietary pattern, in regard to consumption of pepper especially among those with higher education and further study may be necessary in this regard. Though the effect of tea drinking as a risk factor for dyspepsia had not been established as in this study, it has been shown that non-coffee, caffeine- containing beverages like tea and soft drinks are acid secretion stimulators which might predispose to dyspepsia. ${ }^{25}$

The finding of this study, that smoking is not a risk factor predisposing to UD, differed from what was obtainable in other studies in US, UK and India that claimed association between smoking and UD. ${ }^{6,11,12}$ Even though other studies identify it as a clear risk factor for peptic ulcer disease, ${ }^{13}$ it was not seen as a risk factor in functional dyspepsia. ${ }^{9,27}$ This difference could be due to difference in populations of study, in which previous studies were population based while this study was hospital based.

Even though many surveys have associated dyspepsia with alcohol use, and especially studies in 
India and New Zealand ${ }^{4,}{ }^{14}$, this study found there was no association between alcohol use and uninvestigated dyspepsia. This discordance could be due to difference in sociocultural practices of the population of study.

This study showed that non steroidal antiinflammatory drugs use has no association with development of uninvestigated dyspepsia. This is contrary to what was observed in British and American populations based studies where non steroidal anti-inflammatory drugs use have been identified as an important independent risk factor for uninvestigated dyspepsia. ${ }^{6}, 12$ The deduction to support this in a study of Nigerian highlanders where 'indulgence in self medication' was found to be a significant risk factor for $\mathrm{UD}^{16,28}$ may not be absolutely correct, since NSAIDs could not be established as the only medication with tendency to be indulged in, within Nigeria context. The different finding in this study compare to that obtained in Britain and US, could be due to difference in population studied and affordability of NSAIDs compare to those reported.

\section{Conclusion}

This study showed that $H$. pylori infection was not significantly associated with uninvestigated dyspepsia in the population studied. Tea and pepper intake and greater education were significant independent risk factors for uninvestigated dyspepsia.

\section{Acknowledgement}

The authors acknowledge the support given by all the medical, nursing and record staff of the Family Medicine Department of Aminu Kano Teaching Hospital, Kano Nigeria in recruitment of the participants for this work.

The immense contribution of the staff of the Immunology Laboratory of same institution with who screen for Helicobacter pylori was done.

Dr Thomas D Thacher of Mayo Clinic, Rochester, USA, advice in this study from design to analysis will always remain invaluable.

\section{References}

1. National Institute for Clinical Excellence, London. Final Interim Report for Dyspepsia/ Gastro-oesophageal reflux disease August 2005

2. Chiba N. Definitions of Dyspepsia: Time for a Reappraisal. Eur J Surgery 1998; 164 (supp 583): $14-23$
3. Sanjiv M, Khean-Lee G. Epidemiology of functional dyspepsia: A global perspective. World J Gastroenterol 2006; 12(17):2661-2666

4. Shah SS, Bhatia SJ, Mistry FP. Epidemiology of dyspepsia in the general population in Mumbai. Indian J Gastroenterol 2001; 20: 103106

5. Crean GP, Holden RJ, Knill-Jones RP, et al. A database on dyspepsia. Gut 1994 35: 191-202

6. Shaib Y, El-Serag HB. The prevalence and risk factors of functional dyspepsia in a multiethnic population in the United States. Am J Gastroenterol 2004; 99: 2210-2216

7. Caballero-Plasencia AM, Sofos-Kontoyannis S, Valenzuela- Barranco M, Martin-Ruiz JL, Casado-Caballero FJ, Lopez-Manas JG. Irritable bowel syndrome in patients with dyspepsia: a community-based study in southern Europe. Eur J Gastroenterol Hepatol 1999; 11: 517-522

8. Lu CL, Lang HC, Chang FY, Chen CY, Luo JC, Wang SD. Prevalence and health/social impacts of functional dyspepsia in Taiwan: a study based on the Rome criteria questionnaire survey assisted by endoscopic exclusion among a physical check-up population. Scand J Gastroenterol 2005; 40: 402-411

9. Koloski NA, Talley NJ, Boyce PM. Epidemiology and health care seeking in the functional GI disorders: a population-based study. Am J Gastroenterol 2002; 97: 2290-2299

10. Kay L, Jorgensen T. Epidemiology of upper dyspepsia in a random population Prevalence, incidence, natural history and risk factors. Scand J Gastroenterol 1994; 29: 2-6

11. Tougas G, Chen Y, Hwang P, Liu MM, Eggleston A. Prevalence and impact of upper gastrointestinal symptoms in the Canadian population: findings from the DIGEST study. Domestic/ International Gastroenterology Surveillance Study. Am J Gastroenterol 1999; 94: 2845-2854

12. Moayyedi P, Forman D, Braunholtz D, Feltbower R, Crocombc W, Lipptrot M,et.al. The proportion of upper gastrointestinal symptoms in the community associated with Helicobacter pylori, lifestyle factors, and nonsteroidal anti-inflammatory Drugs: Leeds HELP Study Group. Am J Gastroenterol 2000; 95: 1448-1455

13. Aldoori WH, Giovannucci EL, Stampfer MJ, Rimm EB, Wing AL, Willet WC, et.al. A 
prospective study of alcohol, smoking, caffeine and risk of duodenal ulcer in men. Epidemiology 1997; 8: 420-424

14. Haque M, Wyeth JW, Stace NH, Talley NJ. Prevalence, severity and associated features of gastro-oesophageal reflux and dyspepsia: a population-based study. N Z Med J 2000; 113: 178-181

15. Bernersen B, Johnsen R, Straume B. Non-ulcer dyspepsia and peptic ulcer: the distribution in a population and their relation to risk factors. Gut 1996; 38: 822-825

16. Mahadeva S, Goh KL. Epidemiology of functional dyspepsia: A global perspective. World J Gastroenterol 2006; 12 (17): 2661 -2666

17. Hopkins RJ, Girardi LS, Turney EA. Relationship between Helicobacter pylori eradication and reduced duodenal and gastric ulcer recurrence: a review. Gastroenterology 1996; 110: 1244 - 52.

18. Moayyedi P, Forman D, Braunholtz D, Feltbower R, Crocombc W, Liptrott M, et al. The proportion of upper gastrointestinal symptoms in the community associated with Helicobacter pylori, lifestyle factors, and nonsteroidal antiinflammatory drugs. Leeds HELP Study Group. Am J Gastroenterol 2000; 95: $1448-55$.

19. Agreus L, Engstrand L, Svardsudd K, Nyren O, Tibblin G. Helicobacter pylori seropositivity among Swedish adults with and without abdominal symptoms. A population-based epidemiologic study. Scand J Gastroenterol 1995; 30: 752-7.

20. Bernersen B, Johnsen R, Bostad L, Straume B, Sommer AI, Burhol PG. Is Helicobacter pylori the cause of dyspepsia? Br Med J 1992; 304: $1276-9$.

21. Rosenstock S, Kay L, Rosenstock C, Anderson LP, Bonnevie O, Jorgensen T. Relation between Helicobacter pylori infection and gastrointestinal symptoms and syndromes. Gut 1997; 41: 169 $-76$.

22. Stone MA, Barnett DB, Mayberry JF. Lack of correlation between self-reported symptoms of dyspepsia and infection with Helicobacter pylori , in a general population sample. Eur $J$ Gastroenterol Hepatol 1998; 10: 301- 4.

23. Woodward M, Morrison CE, McColl KE. The prevalence of dyspepsia and use of antisecretory medication in North Glasgow: role of Helicobacter pylori vs. lifestyle factors. Aliment Pharmacol Ther 1999; 13: 1505 -9.

24. Talley NJ, Stanghellini V, Heading RC, Koch KL, et al. Functional Gastroduodenal disorders. Gut 1999; 45: 37-42

25. Marotta RB, Floch MH. Diet and nutrition in ulcer disease. Med Clin North Am 1991; 75(4): 967-79

26. Michael Ayad. Do Chilli peppers cause Ulcer? - A burning question. Nutrition Bytes 1995; 1: 15

27. Li Y, Nie Y, Sha W, Su H. The link between psychosocial factors and functional dyspepsia: an epidemiological study. Chin Med J (Engl) 2002; 115: 1082-1084

28. Ihezue CH, Oluwole FS, Onuminya JE, Okoronkwo MO. Dyspepsia among highlanders of Nigeria: an epidemiological survey. Afri J Med Sci 1996; 25(1):23-29 